\title{
Determining the Optimal Parameter of Coordinate Measuring Machine with Design of Experiment
}

\author{
Kusalin Sangnuan and Wimalin S. Laosiritaworn \\ Department of Industrial Engineering, Faculty of Engineering, Chiang Mai University, Thailand
}

\begin{abstract}
Coordinate measuring machine (CMM) is a device used to measure physical geometry of object. It has been used widely in industry for quality control and monitoring of production process due to its high accuracy and precision. Measurement accuracy is very crucial in quality inspection as measurement result is used to decide if the product should become defect. CMM accuracy depends on several factors such as probe size, number of touching point and measurement speed. This research applied design of experiment technique to optimize setting of those parameters to obtain high measurement accuracy. A case study from swage hole measurement of hard disk drive actuator arm was use to demonstrate the proposed technique. The result showed that CMM accuracy of the case study company was significantly increased after CMM has been set with parameters optimized with design of experiment.
\end{abstract}

\section{Introduction}

Measurement systems is very crucial in controlling product quality. Coordinate measuring machine (CMM) is a device used to measure geometry characteristic of an object by moving a measuring probe to contact points on object surface. It is widely used in most manufacturing factory as it can be used to measure almost any kind of object 1 . CMM has been an important inspection tool in quality control due to its high accuracy and precision 2. It is the main measurement instrument used to measure object geometry in the case study company who is a manufacturer of actuator arm for hard disk drive component (Fig. 1a). Actuator arm is a part of hard disk that read/write arm is attached. It is used to move the head arm to different track on the surface of the platter. One of the most important part in actuator arms is swage hole (Fig. 1b). Swage hole attach head gimbals assembly (HGA) with carriage. In assembly process, swage ball is pressed into swage hole with swage pressing machine. If the swage hole is too big, HGA will not able to hold on to carriage. On the other hand, if the swage hole is too small, it will not be possible to insert HGA into swage hole.

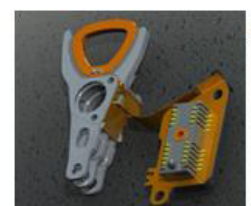

a) Actuator arm

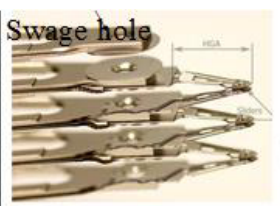

b) Swage hole

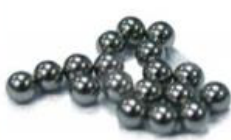

c) Swage ball
Figure 1. Component of hard disk drive actuator
Design of experiment (DoE) is a "process of planning the experiment so that appropriate data that can be analyzed by statistical methods will be collected, resulting in valid and objective conclusions" 3 . It can be used to statistically investigate the effect of independent factors on dependent factors. DoE has been applied successfully to optimize actuator productions for example design of a small linear actuator 4, actuator coil baking 5 .

This paper investigated the effect of CMM measurement setting on the swage hole measurement accuracy. The objective of this research is to find the optimum setting that provide swage hole geometry as close as possible to reamer tool used to manufacture that hole.

\section{Research methodology}

This research starts with the review of literature about the factors affecting CMM measurement accuracy. After preliminary analysis three factors namely probe size, number of measurement point, measurement speed were selected. Length of probe was fixed at the case study company therefore was not included in the experiment.

The level setting of these parameters. For factor A, the probe size, as there are only two size of probe, Probe size level was set at 0.5 millimeter for low level and 1 millimeter for high level. Factor $\mathrm{B}$ is number of measurement point. It was set at 8 points for low level and 16 points for high level. Finally factor $\mathrm{C}$, the measurement speed. This factor was set to the lowest and highest possible setting of the machine, which was low level at 1 millimeter/sec and high level at 8 millimeter $/ \mathrm{sec}$.

$2^{3}$ factorial design was used to generate experimental setting. Minitab software was used for design and analysis 
of experiments in this research. Sample of actuator arm was prepared with the same reamer to block the effect of tooling variation. Diameter and roundness of this reamer was measured with smart scope which has accuracy of 0.0005 millimeter. This standard reamer has 2.668 millimeter in diameter and 0.001 millimeter roundness. This reamer was installed into $\mathrm{CNC}$ machine and used to drilled numbers of swage hole for each experimental setting. We set three sample were taken from the group of actuation that has flatness, roll and pitch at medium, higher and lower than specification. Measurement by CMM for each sample was repeated 5 times.

Two responses were consider in this experiment. The first response was diameter deviation which was calculated from the difference between actual reamer diameter $(2.668$ millimeter) and the diameter measurement from CMM. Second response was roundness deviation which was the difference between actual reamer roundness $(0.001$ millimeter) and roundness measured from CMM.

\section{Results and discussions}

$2^{3}$ factorial design requires 8 experimental run. For each experimental setting, 3 actuator arms were sampled. Measurement of diameter and roundness were repeated five times.

\subsection{Residual analysis}

ANOVA analysis has basic assumption that the observations are adequately described by the model, the errors are normally and independently distributed with mean zero and constant but unknown variance 3 . To test those assumption, residual analysis was performed. Normal probability plot for both diameter deviation and roundness deviation form straight lines which suggested that the residuals are normally distributed. The residuals versus fitted values for both diameter deviation and roundness deviation do not has particular trend. This is the same as residual versus the order of the data graph, which suggested that residuals were independent from observation order. After all assumptions were checked, ANOVA can be used for data analysis.

\subsection{Analysis of variance (ANOVA)}

Table 1 shows analysis of variance result of diameter deviation. Blocks, main effects, and 2-way interactions have significant effect on diameter deviation at $95 \%$ confidence as they have $P$ value less than 0.05 .

Table 2 shows estimated effect of coefficients for diameter deviation. Factor $\mathrm{A}, \mathrm{C}$ and $\mathrm{AC}$ interaction has significant effect on diameter deviation at $95 \%$ confident as they have $\mathrm{P}$ value less than 0.05 .

Regression equation was fitted with significant terms from Table 2 (factor $\mathrm{A}, \mathrm{C}$ and $\mathrm{AC}$ interaction). The equation to predict $Y_{l}$ (diameter deviation) is as follow;

$Y_{l}=0.00415+0.002033 \mathrm{~A}+0.001567 \mathrm{C}+0.000217 \mathrm{AC}$

Table 1. Analysis of variance for diameter deviation

\begin{tabular}{|l|l|l|l|l|l|l|}
\hline Source & DF & Seq SS & Adj SS & Adj MS & F & P \\
\hline Blocks & 2 & $2.32 \mathrm{E}-05$ & $2.32 \mathrm{E}-05$ & $1.16 \mathrm{E}-05$ & 71.6 & $0.000^{*}$ \\
\hline Main Effects & 3 & 0.000791 & 0.000791 & 0.000264 & 1630.24 & $0.000^{*}$ \\
\hline 2-Way Interactions & 3 & $5.7 \mathrm{E}-06$ & $5.7 \mathrm{E}-06$ & $1.9 \mathrm{E}-06$ & 11.75 & $0.000^{*}$ \\
\hline 3-Way Interactions & 1 & 0.000 & 0.000 & 0.000 & $*$ & $*$ \\
\hline Residual Error & 110 & $1.78 \mathrm{E}-05$ & $1.78 \mathrm{E}-05$ & $1.6 \mathrm{E}-07$ & & \\
\hline Lack of Fit & 14 & $4.98 \mathrm{E}-06$ & $4.98 \mathrm{E}-06$ & $3.6 \mathrm{E}-07$ & 2.67 & 0.002 \\
\hline Pure Error & 96 & $1.28 \mathrm{E}-05$ & $1.28 \mathrm{E}-05$ & $1.3 \mathrm{E}-07$ & & \\
\hline Total & 119 & 0.000837 & & & & \\
\hline
\end{tabular}

Table 2. Estimated effects of coefficients for diameter deviation.

\begin{tabular}{|l|l|l|l|l|l|}
\hline Term & Effect & Coef & SE Coef & T & P \\
\hline Constant & & 0.00415 & 0.000037 & 113.07 & 0.000 \\
\hline Block 1 & & -0.000025 & 0.000052 & -0.48 & 0.631 \\
\hline Block 2 & & 0.00055 & 0.000052 & 10.60 & $0.000^{*}$ \\
\hline A & 0.004067 & 0.002033 & 0.000037 & 55.40 & $0.000^{*}$ \\
\hline B & 0.000000 & 0.000000 & 0.000037 & 0.00 & 1.000 \\
\hline C & 0.003133 & 0.001567 & 0.000037 & 42.68 & $0.000^{*}$ \\
\hline$A^{*} B$ & 0.000033 & 0.000017 & 0.000037 & 0.45 & 0.651 \\
\hline$A^{*} \mathrm{C}$ & 0.000433 & 0.000217 & 0.000037 & 5.90 & 0.000 \\
\hline$B^{*} \mathrm{C}$ & 0.000033 & 0.000017 & 0.000037 & 0.45 & 0.651 \\
\hline
\end{tabular}




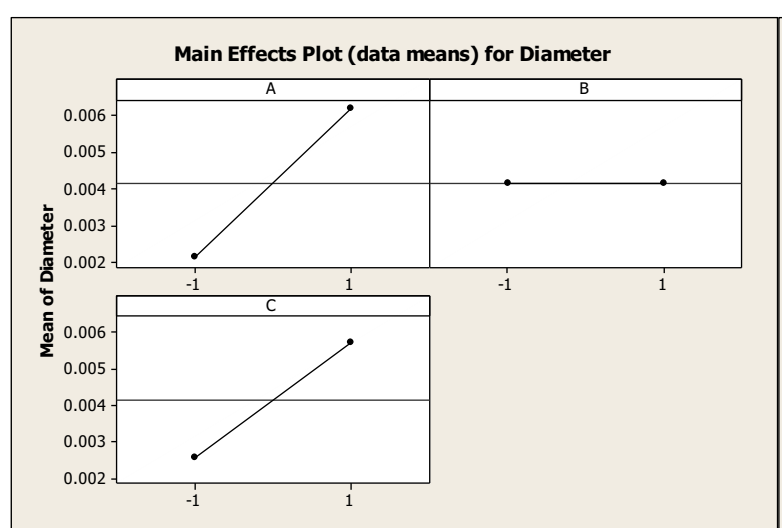

a) Main effects plot of data mean

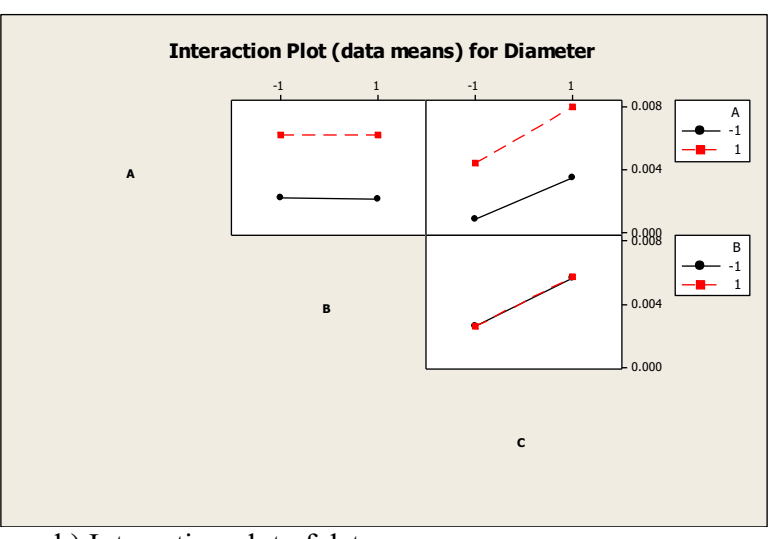

b) Interaction plot of data mean

Figure 2. Main effects plot and interaction plot of data means for diameter deviation response

Fig. 2a) is the main effects plot that show the different between means of each level for every factors. As factor B is not significant, it shows almost no different in mean between low and high level (the plot is horizontal). On the other hand, factor $\mathrm{A}$ and $\mathrm{C}$ are significant as the line is not horizontal. Smaller mean deviation is more desirable, so factor $\mathrm{A}$ and $\mathrm{C}$ should be set at low level.

Fig. 2b) is the interaction plot of data mean represents the interaction between a pair of factors. For example, interaction between factor $\mathrm{A}$ and $\mathrm{B}$ is calculated from the average over the remaining parameter. $\mathrm{AB}$ and $\mathrm{BC}$ interaction do not show significant interaction as both line are in parallel. AC interaction, on the other hand, is significant and the optimum setting of $\mathrm{AC}$ is at low level for both factor $\mathrm{A}$ and factor $\mathrm{C}$.

The same procedures were repeated for the second response (roundness deviation). Residual analysis showed that the residual are normally distributed with no particular trend in both residual versus fitted values and residual versus the order of the data, therefore, passed ANOVA assumption. ANOVA results suggested that AC interaction is significant to roundness deviation at $95 \%$ confidence. The equation to predict $Y_{2}$ (roundness deviation) is as follows,

\section{$Y_{2}=0.001292+0.000075 \mathrm{~A}+0.000025 \mathrm{C}-0.00013 \mathrm{AC}$}

Response optimizer in Minitab was used to find the optimum setting. It was found that the best setting is at diameter of 0.5 millimeter, 16 measurement point with measurement speed of 1 millimeter/sec. 15 confirmation experiments were conducted using the optimum setting. The average response for both diameter deviation and roundness were 0.001 millimeter which is considered very accurate.

\section{Literature References}

There has been a number of reports on improving CMM efficiency. For example, Miller et al. 6 studied the effect of stylus diameter used for probing in CMM in order to obtain the effective stylus diameter. Mian et al. 2 reduced measurement cycle time by generating the most suitable measurement path. A number of factors that could have impact on CMM measurement accuracy can be summarized as follows;
Probe size. Rajamohan et al. [7]. studied effect of probe size on measuring free form profile and conclude that smaller probe size provide more accuracy. This result is consistent with Ayub et al. 8 where roundness tolerance was investigated.

Number of measurement point. Measurement error is high if small number of measurement point were taken. This is due to the lack of stability in the approximation area of the interpolation methods 8 .

Measurement speed. Measurement speed is the time taken for measurement probe to touch the object. With fast measurement speed, the probe might touch the object harder which could leads to higher measurement error [8].

Length of probe. Probe errors usually increase with the length of the stylus 9 .

\section{Summary}

This paper present an improvement of CMM accuracy with design of experiment technique. Factors that could have impact on CMM measurement was surveyed in literature. Three factors adopted were probe size, number of measurement point and measurement speed. It was found that number of measurement point has no significant effect on accuracy while probe size and measurement speed are significant. Smaller probe size $(0.5$ millimeter $)$ provide significant improve in measurement accuracy. This result is in consistent with Rajamohan et al. [7]. and Ayub et al. 8. Lower measurement speed (1 millimeter/sec) provides better accuracy. These new setting results in both diameter and roundness deviation of 0.001 millimeter which is considered significant improvement in this case.

\section{References}

1. J. Ni and F. Waldele, Coordinate measuring machines, in: J. A. Bosch (Ed), Coordinate measuring machines and system, Marcel Dekker Inc., New York (1995)

2. Mian, S.H. and A. Al-Ahmari, Enhance performance of inspection process on Coordinate Measuring Machine. Measurement, 4,78-917, (2014)

3. D.C. Montgomery, Design and Analysis of Experiments. John Wiley \& Sons, New York, (2005)

4. D.J. Lee, K.S. Wo, N.C. Park, and Y.P. Park. Design and optimization of a linear actuator for subminiature 
optical storage device. IEEE Trans of Magnatics. 41, 1055-1057, (2005)

5. Punnarungsri, P. and W. Laosiritaworn. Optimization of coil baking parameters using design of experiments. in Lecture Notes in Engineering and Computer Science. 933-937, (2013)

6. J. Miller, S. Dutta, E. Morse, and J. Yague-Fabra, Effective stylus diameter determination using near zero-width reference, Precision Engineering, 35, 500-504, (2011)

7. Rajamohan, G., M.S. Shunmugam, and G.L. Samuel, Effect of probe size and measurement strategies on assessment of freeform profile deviations using coordinate measuring machine. Measurement, 4, 4832-841, (2011)

8. Ayub, M.A., A.B. Mohamed, and A.H. Esa, Experimental Investigation on the Measurement of Roundness Tolerance. European Journal of Scientific Research, 65, 304-311, (2011)

9. Wozniak, A. and M. Dobosz, Factors influencing probing accuracy of a coordinate measuring machine., IEEE Transactions on Instrumentation and Measurement, 54: 2540-2548, (2005) 